\title{
Modified Bean Seed Protein Phaseolin Did Not Accumulate Stably in Transgenic Tobacco Seeds after Methionine Enhancement Mutations
}

\author{
Eric Lasserre', ${ }^{1,2}$ T. S. Ko1, John M. Dyer ${ }^{1,3}$, Norimoto Murai ${ }^{1}$ \\ ${ }^{1}$ Department of Plant Pathology and Crop Physiology, Louisiana State University and LSU Agricultural Center, \\ Baton Rouge, LA, USA \\ ${ }^{2}$ Laboratoire Genome et Developement des Plantes, Universite de Perpignan, Perpignan, France \\ ${ }^{3}$ Plant Physiology and Genetic Research Unit, US Arid-Land Agricultural Research Center, USDA-ARS, Maricopa, AZ, \\ USA \\ Email: nmurai@Isu.edu
}

Received 11 February 2015; accepted 14 March 2015; published 17 March 2015

Copyright (C) 2015 by authors and Scientific Research Publishing Inc.

This work is licensed under the Creative Commons Attribution International License (CC BY). http://creativecommons.org/licenses/by/4.0/

(c) (i) Open Access

\section{Abstract}

The major seed storage protein phaseolin of common bean (Phaseolus vulgaris L.) is deficient in methionine, an essential amino acid for human and animal health. To improve the nutritional quality of common bean, we designed methionine enhancement of phaseolin based on the threedimensional structure of protein, de novo design principles and genetic information. Amino acid substitution and loop insertion were targeted to the interior and exterior, respectively, of the protein's $\beta$-barrels. First, we introduced the methionine enhancement mutations into phaseolin cDNA, expressed cDNA in Escherichia coli and purified monomeric non-glycosylated proteins. Biophysical analysis of $E$. coli-expressed proteins demonstrated a similar structural stability of wildtype and mutant phaseolin monomers. Here, we attempted to test the structural stability of the methionine-enhanced phaseolin by introducing phaseolin cDNA to tobacco via Agrobacterium tumefaciens-mediated transformation of leaf disks, regenerating transgenic tobacco plants, and examining the accumulation of phaseolin protein in mature transgenic tobacco seeds. We used seven constructs containing different extents of methionine enhancement, ranging from the original 3 to maximum 33 methionines per 397 amino acid residues. ELISA analyses indicated that the methionine-enhanced phaseolins did not accumulate as stably in mature transgenic tobacco seeds as the wild-type phaseolin. It seems likely that the methionine-enhanced phaseolin proteins were under the stringent scrutiny of the protein quality control mechanism in the endoplasmic reticulum (ER), Golgi complex and/or vacuolar protein bodies. The protein degradation is probably to occur in the vacuolar protein bodies due to the instability of the trimer assembly caused by the methionine enhancement mutations targeting either amino-acids substitutions or/and loop inser- 
tions to the interior $\beta$-sheets and tum/loop regions, respectively, of $\mathrm{N}$ - and $\mathrm{C}$-barrel structures.

\title{
Keywords
}

\author{
Common Bean, Glycosylation, Methionine Enhancement, Phaseolin, Polypeptide Folding, Trimer \\ Assembly
}

\section{Introduction}

Seed storage proteins of legumes and cereals are the major protein sources for human and domesticated animals. Because of the high level of expression and subsequent accumulation of these proteins, they determine the nutritional value of the seed. Consistent with their role as a reserve of nitrogen, they are rich in nitrogen-containing amino acids and generally deficient in essential amino acids such as lysine and threonine in cereals and sulfur-containing amino acids, methionine and cysteine in legumes. In attempts to improve the nutritional value of crops grains, conventional breeding programs had been largely unsuccessful [1] [2]. Genetic engineering is an alternative approach that allows the direct modification of storage proteins genes to improve their amino acid composition. For that purpose, we initiated a work on structural modification of phaseolin for methionine enhancement [3] [4].

Phaseolin, a 7S vicilin-type of globulins, accounts for roughly half of the total seed protein content of common bean (Phaseolus vulgaris L.) [5]. It is a trimeric protein composed of three similar glycosylated polypeptides that accumulate in the vacuolar protein bodies of developing cotyledons [6]. Phaseolin is encoded by six to eight genes per haploid bean genome and consists of nearly identical $\alpha$ - and $\beta$-polypeptides [7]. The $\alpha$-phaseolin (411 - 412 amino acid residues) and $\beta$-phaseolin gene (397 amino acid residues) share 98\% identity with an exception of 18 amino acid insertion at the C-terminal end of $\alpha$-phaseolin gene [8]. Both phaseolin protein and genes have been isolated and characterized [9]-[11]. The phaseolin gene expression is temporally and spatially regulated [12] [13].

First efforts toward protein engineering of seed storage proteins in general and phaseolin in particular have been frustrated by the lack of accurate structural information of the target proteins and by the inability to characterize structural alterations brought about by the introduced mutations. This is illustrated by an initial attempt to insert methionine-rich $\alpha$-helix-forming sequence (Hoffman insert) into an N-terminal Helix-Turn-Helix (HTH) motif ( $\alpha$-helix-2) of phaseolin [14]. The mutation resulted in a 50-fold reduction in the protein accumulation in transgenic tobacco seeds.

Learning from the previous limitations, we developed a four-step strategy for the improvement of the amino acid content of phaseolin, based on three-dimensional structural information now available after X-ray crystallographic analysis of the protein [15] [16]. The first step was structure-based protein design and its refinement by computer simulation. The complete three-dimensional structure of phaseolin was generated from $\alpha$-carbon coordinates by using molecular mechanic calculations and this structure was used as a template to simulate modifications aimed at increasing the methionine content of the protein [3]. Two strategies were retained which consist in targeting amino-acids substitutions and loop insertions to the interior $\beta$-sheets and turn/loop regions, respectively, of $\mathrm{N}$ - and $\mathrm{C}$-barrel structures, bringing the methionine content from original 3 to maximum 33 per 397 amino-acid residues. Stability of the mutant proteins was tested by molecular dynamic simulation [3]. In the second step, some predicted neutral methionine enhancement mutations were introduced into phaseolin cDNA by site-directed mutagenesis and the mutated genes expressed in E. coli to assess the mutation's effects on protein folding and stability [4]. Structural analysis of these E. coli-expressed proteins, using a set of previously developed biophysical probes, indicated a similar stability of the wild-type and mutant proteins [4] [17].

These preliminary studies have thus provided us with strong evidence for structural stability of methionineenhanced phaseolins and paved the way for the last step, their reintroduction into plants. At this stage of the study, the homologous host was not chosen because production of transgenic beans is still a very time-consuming process and only a few constructs may be tried at a time. Moreover, the presence of wild-type phaseolin in beans makes the task of detection and characterization of mutant proteins much more difficult. In contrast, Agrobacterium-mediated transformation and transgenic plant production of tobacco are very efficient, and tobacco lacks expression of phaseolin. In addition, tobacco has proven to be a suitable host for correctly regulating 
and targeting either wild-type phaseolin [18] [19] and $\beta$-conglycicnin [20] or tryptophan-enhanced 2S albumins [21]. Finally, expression of wild-type phaseolin in transgenic tobacco seeds has been well characterized by our laboratory [13] [22] [23]. Therefore, in a preliminary step towards improvement of common beans, we will assay the expression of phaseolin mutant cDNAs in tobacco seeds for the protein synthesis and stability, posttranslational modification, transport and storage in the vacuolar protein bodies.

The basic strategy is to test four representative constructs among the methionine-enhanced phaseolin genes previously expressed in E. coli [4]. First, the expression cassettes have been reconstructed to be suitable for introduction and expression of mutated phaseolin genes in tobacco seeds. Then, tobacco leaf disks have been transformed using binary Ti vectors of Agrobacterium tumefaciens [22]. Here, we report the regeneration of transgenic tobacco plants carrying those methionine-enhanced phaseolin constructs, and the initial analysis of phaseolin accumulation in mature tobacco seeds by enzyme-linked immunosorbent assay (ELISA).

\section{Materials and Methods}

\subsection{Construction of Methionine-Enhanced Phaseolin Genes and Transformation Vectors}

E. coli host strains $\mathrm{DH} 5 \alpha$, XL1 Blue or HB 101 were transformed by electroporation using an E. coli Pulser (Bio-Rad) according to manufacturers instructions. All modifying and restriction enzymes were purchased from New England Biolab (NEB) and Bethesda Research Laboratories (BRL). Plasmid constructions, extractions and analysis were performed according to classical methods [24].

A 2.4 kb EcoRI/BamHI restriction fragment from pTRA322, containing the phaseolin coding and 3'-downstream sequence, was cloned into pBluescript KS-vector (Strategene) to generate pTSK1. A Bglll site was created at Nsil site by digestion of pTSK1 with Nsil and insertion of an Nsi1/Bglll linker (annealed oligonucleotides 5'-TAGATCTTGCA-3' and 5'-AGATCTATGCA-3') that has Nsil compatible ends. The new plasmid was called pTSK2. A 1.3 kb EcoRI fragment from pUC4K-KSAC, containing a bacterial-expressible kanamycin-resistance gene, was inserted into the EcoRI site of pTSK2 to generate pTSK3. The 5'-end of the phaseolin gene, including the $782 \mathrm{bp}$ promoter region and signal peptide, was then restored by subcloning a $1.3 \mathrm{~kb} \mathrm{HindIII} /$ EcoRI restriction fragment from pTRA322 into pTSK3, resulting in pTSK4.

The methionine-enhanced phaseolin constructs to be inserted are constructs 7 (2 loop-insertions), 15 (C-terminal 10 methionine-substitutions), 17 (C- and N-terminal 20 methionine-substitutions), and 20 (2 loop-insertions and 20 methionine-substitutions) as illustrated in Figure 1. Construct 2 (original wild-type cDNA with new restriction sites for mutagenesis that is referred as wild-type thereafter) and construct 9 (Hoffman insertion) were used as positive and negative controls, respectively. The mutated phaseolin genes were obtained from pMal-PF clones. These clones were originally constructed by Dyer et al. [4] for expression in E. coli, and the N-terminal signal peptide sequence had been removed. Therefore, a $1.3 \mathrm{~kb}$ EcoRI/BamHI restriction fragment from pTAM-pps, containing the original signal peptide sequence, the 2 loop-insertion mutation and BssHII and Smal sites that will be used to introduce the other methionine-enhanced phaseolin cDNA constructs, was inserted into pTSK4 to generate pTSK5-7. The $1.2 \mathrm{~kb}$ BssHII/Smal fragments from each pMal-PF2, 9, 15, 17 and 20 were then used to replace the BssHII/Smal from pTSK5-7 to generate pTSK5-9, 15, 17, and 20, respectively. The 3.7 kb HindIII/BamHI fragments from pTSK5-7, 9, 15, 17 and 20, containing methionine-enhanced phaseolin genes, were cloned into the HindIII/BamHI sites of pTRA231 which contains the plant-expressible kanamycin-resistance gene. The resulting plasmids were called pTSK6-2, 7, 9, 15, 17 and 20.

To facilitate the selection of the subsequent constructions, a bacterial-expressible kanamycin-resistance gene was inserted into the EcoRI sites of each pTSK6 clones to generate pTSK7-2, 7, 9, 15, 17 and 20. Then, the 6.6 $\mathrm{kb}$ Bglll fragment of each pTSK7 clones was cloned into the Bglll-digested binary vector pTRA408 and the so-called pTSK8 clones were selected for resistance to both tetracycline and kanamycin. The removal of the bacterial kanamycin-resistance gene with EcoRI-digestion followed by self-ligation generated pTSK9-2, 7, 9, 15, 17 and 20, then renamed pTRA 451, 452, 453, 454, 455, and 456 respectively, as shown in Figure 1.

Constructs were checked by restriction analysis at each step and by sequencing the pTSK6 clones using a Dye Terminator Cycle Sequencing kit and an ABI Prism 310 Genetic Analyser (Perkin Elmer).

\subsection{DNA Extraction and PCR Analysis}

To confirm the introduction and integrity of binary vector in Agrobacterium, bacteria were grown overnight in 5 $\mathrm{ml}$ of LB containing $10 \mu \mathrm{g} / \mathrm{ml}$ of tetracycline, $20 \mu \mathrm{g} / \mathrm{ml}$ of rifampicin and $250 \mu \mathrm{g} / \mathrm{ml}$ of streptomycin. For plas- 


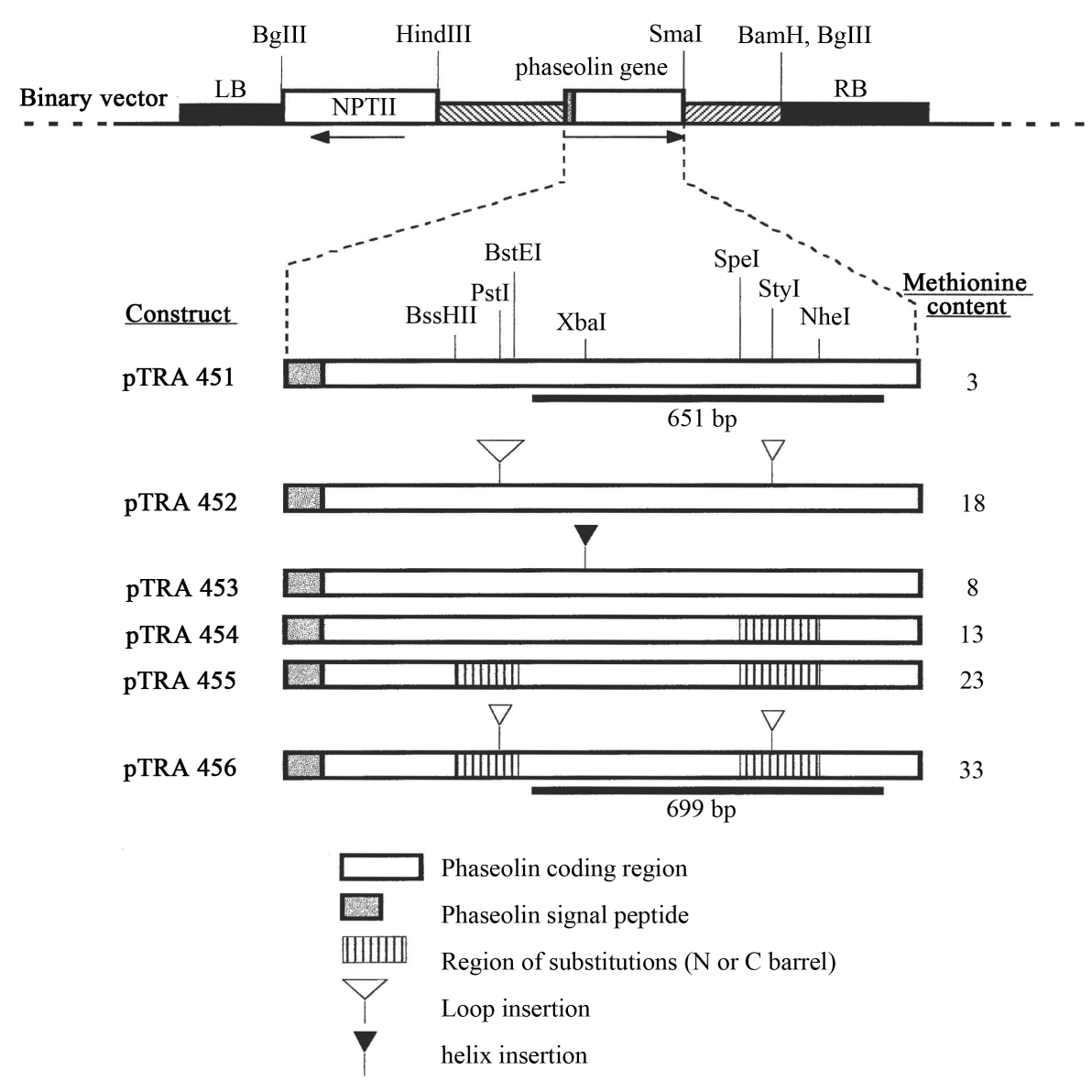

\begin{abstract}
Figure 1. Schematic diagram of six binary transformation vectors pTRA451 to 456 , and the types of methionine-enhancement mutations illustrated in the phaseolin coding regions. Binary vectors of Ti plasmid in Agrobacterium tumefaciens were used to transform tobacco leaf discs. The T-DNA of vector consists of the left boarder (LB) and right boarder (RB) sequences, the neomycin phosphotransferase II gene for the kanamycin resistance selection in plants, and the bean seed storage protein phaseolin gene under the control of 782 bp 5'-upstream promoter sequences and $1.5 \mathrm{kbp} 3$ '-downstram sequences. Wild type pTRA 451 is a positive control containing the wild-type coding sequence of phaseolin slightly modified by new restriction sites for construction. Construct pTRA 453 is a negative control with the "Hoffman insert" in the N-terminal Helix-Turn-Helix (HTH) motif ( $\alpha$-helix-2). Constructs pTRA 454 and 455 have the replacement mutations, the former with 10 methionine substitutions in C-terminal $\beta$-barrel and the latter with 10 methionine substitution mutations in both $\mathrm{N}$ - and C-terminal $\beta$-barrel structures. Construct pTRA 452 has the methionine enriched insertions into loops of $\mathrm{N}$ - and C-terminal $\beta$-barrel structures. Construct pTRA 456 has a combination of the methionine-substitution and loop insertion mutations.
\end{abstract}

mid extraction, bacteria from $3 \mathrm{ml}$ cultures were pelleted and re-suspended in $1 \mathrm{ml}$ of TE (10 mM Tris- $\mathrm{HCl} \mathrm{pH}$ 8.0, $1 \mathrm{mM}$ EDTA). N-lauroylsarcosine was added at $0.5 \%(\mathrm{w} / \mathrm{v})$ final concentration and the tubes incubated 2 minutes at room temperature. The bacteria were pelleted and plasmid DNA was then prepared as for E. coli, using an alkaline lysis procedure [24]. The DNA was finally re-suspended in $20 \mu \mathrm{l}$ of water and $10 \mu \mathrm{l}$ were used for digestion with restriction enzyme. For total DNA extraction, cells from an overnight $1.5 \mathrm{ml}$ culture were pelleted and re-suspended in $340 \mu \mathrm{l}$ of TE. N-laurylsarcosine and proteinase $\mathrm{K}$ were added at $0.8 \mu \mathrm{g} / \mathrm{ml}$ final concentration and the tubes incubated for 1 hour at $37^{\circ} \mathrm{C}$. Chromosomal DNA was broken by pipetting up and down through a needle with a syringe, extracted once with one volume of phenol/chloroform and used for PCR analysis. DNA was further purified with several subsequent chloroform extractions for Southern blot analysis.

PCR analysis were performed in standard conditions on either plasmids or total DNA preparations described 
earlier, with the following cycling conditions: 1 cycle at $96^{\circ} \mathrm{C}, 3 \mathrm{~min}$; 30 cycles at $96^{\circ} \mathrm{C}, 15 \mathrm{sec}$; SOC, $30 \mathrm{sec}$; $72^{\circ} \mathrm{C}, 1 \mathrm{~min}$ and 1 cycle at $72^{\circ} \mathrm{C}, 5 \mathrm{~min}$. Primers were PSP 79 (5'-GTCCAGAGCTCTACCGATGCT-3') and PSP 84 (5'-CAACTCGCCATGCCCGTTAAC-3') that amplify a fragment of 651 bp from pTRA 451, 454 and 455, and a longer fragment of 699 bp from pTRA 452, 453 and 456.

DNA from plants was extracted as described previously [25]. Briefly, a small leaf disk was grinded in $200 \mu \mathrm{l}$ of $0.5 \mathrm{~N} \mathrm{NaOH}$. A $5 \mu \mathrm{l}$ aliquot was diluted in $500 \mu \mathrm{l}$ of $100 \mathrm{nM}$ Tris-HCI $\mathrm{pH}$ 8. One $\mu \mathrm{l}$ of this solution was used as a template for PCR analysis. Cycling conditions were as follows, using Taq polymerase from Epicenter (l× buffer, $3 \times$ Master Amp, $5 \mathrm{mM} \mathrm{MgC1}_{2}$ ): 1 cycle at $95^{\circ} \mathrm{C}, 2 \mathrm{~min} 30 \mathrm{sec}, 40$ cycles at $95^{\circ} \mathrm{C}, 30 \mathrm{sec} ; 68^{\circ} \mathrm{C}, 1 \mathrm{~min}$; $72^{\circ} \mathrm{C}, 1 \mathrm{~min}$ and $1 \mathrm{cycle}$ at $72^{\circ} \mathrm{C}, 5 \mathrm{~min}$. The primers are described above and were used at a concentration of $0.01 \mu \mathrm{M}$.

\subsection{Transformation and Regeneration of Transgenic Tobacco Plants}

The cultivar Xanthi of Nicotiana tabacum L. was used in this study. Sterile seedlings were grown in MS medium as previously described for 4 to 5 weeks, and in vitro grown plants were used as a source of leaf disks for transformation [22]. Agrobacterium tumefasciens strain PC2760 was transformed by electroporation with the wild type (pTRA 451) or methionine-enhanced phaseolin genes constructs (pTRA 452, 453, 454, 455 and 456) were transferred. Transgenic tobacco plants were regenerated by a modified leaf disk method as described [22]. From 9 to 35 independently transformed plants per construct were grown in a greenhouse. Mature seed capsules were collected from each transgenic plant four-weeks after hand-pollination and stored at $-70^{\circ} \mathrm{C}$ for further analysis.

\subsection{ELISA Determination of Phaseolin Concentration}

Seeds from mature capsules were ground in a mortar and pestle, extracted for 5 min with acetone and reground. Approximately $10 \mathrm{mg}$ of ground seeds were extracted twice for $1 \mathrm{~h}$ with $0.5 \mathrm{ml}$ of PBS containing $0.02 \%(\mathrm{w} / \mathrm{v})$ $\mathrm{NaN} 3$, as described by Burow et al. [13]. The phaseolin concentrations were determined using phaseolin-specific antibody in antibody-sandwich ELISA essentially performed using skim milk as a blocking agent. Total protein concentration was determined using a BioRad DC protein assay.

\section{Results}

To improve the nutritional quality of common bean we designed methionine enhancement of the major seed storage protein phaseolin, based on the three-dimensional structure of protein, de novo design principles and genetic information. Amino acid substitution and loop insertion were targeted to the interior and exterior, respectively, of the two $\beta$-barrel structures of phaseolin. First, we introduced the methionine enhancement mutations into phaseolin cDNA, expressed cDNA in Escherichia coli and purified monomeric non-glycosylated proteins. Biophysical analysis of E. coli-produce proteins indicated a similar structural stability of wild-type and mutant phaseolin monomers [4].

Here, we attempted to test the structural stability of the methionine-enhanced phaseolin protein by introducing phaseolin cDNA to tobacco via Agrobacterium tumefaciens-mediated transformation of leaf disks, regenerating transgenic tobacco plants, and comparing the accumulation level of phaseolin protein in mature transgenic tobacco seeds four weeks after hand-pollination.

\subsection{Methionine Enhancement Constructs}

We prepared six constructs containing different extent of methionine enhancement, ranging from the original 3 to maximum 33 methionines per 397 amino acid residues, as shown in Figure 1. These constructs were derived from methionine-enhanced cDNA previously used for the expression studies in E. coli. Wild type pTRA 451 is a positive control containing the wild type coding sequence of phaseolin slightly modified by new restriction sites for construction. Construct pTRA 453 is a negative control with the "Hoffman insert" which resulted in the 50 -fold reduction of the phaseolin accumulation in mature tobacco seeds [14].

Four constructs pTRA 452, 454, 455 and 456 have the methionine enhancement mutations in the coding region and the protein expression levels are to be tested at this study. Constructs pTRA 454 and 455 have the replacement mutations expected to provide more stable proteins in plants, the former with 10 methionine-substi- 
tutions in C-terminal $\beta$-barrel and the latter with 10 methionine substitution mutations in both $\mathrm{N}$-and C-terminal $\beta$-barrel structures. Construct pTRA 452 has the methionine enriched insertions into loops of $\mathrm{N}$-and C-terminal $\beta$-barrel structures. Construct pTRA 456 has a combination of the methionine-substitution and loop-insertion mutations, maximizing the methionine enrichment to the total methionine content of 33 per polypeptide.

\subsection{Transformation and Regeneration of Transgenic Tobacco Plants}

The wild-type and mutated phaseolin coding sequences have been placed under the control of the 782 bp promoter and signal peptide, and $1.5 \mathrm{kbp}$ 3'-downstream region of the phaseolin gene [11] (Figure 1). These phaseolin gene cassettes have been inserted into a binary vector pTRA408 together with a plant-expressible kanamycin resistance gene (NPTII). Tobacco has been transformed via A. tumefasciens strain PC2760, using a modified leaf disk method [22]. Transformed calli/plants were initially selected on the basis of resistance to 300 $\mathrm{mg} / \mathrm{L}$ of kanamycin in the selection media, and confirmed by positive PCR-amplification signals of the phaseolin coding sequence in the DNA samples of leaf extracts (Figure 2). Kanamycin-resistant plants were regenerated from independently transformed calli, and a total of 115 of fertile tobacco plants were grown to the maturity in the green house. Mature seed capsules were harvested four weeks after hand-pollination (Table 1).

\subsection{Genomic DNA Analysis of the Phaseolin Genes in Tobacco Leaves}

The presence of the methionine-enhanced phaseolin genes was tested by PCR in the genomic DNA extracts from transgenic tobacco leaves. The primers used (see Materials and Methods) should amplify a segment of the C-terminal half of the genes and allowed to distinguish pTRA 451, 454 and 455 (the amplified fragment is 651 bp in length) from pTRA 452, 453 and 456 (699 bp in length) as illustrated in Figure 1. Figure 2 demonstrates the $2 \%$ agarose gel electrophoresis analysis of PCR products for one representative sample for each of six constructs. PCR signals were detected in 89 plant extracts out of 115 plants tested, with the 651 or 699 bp fragment amplified by PCR.

\subsection{Phaseolin Protein Accumulation in Mature Transgenic Tobacco Seeds}

Enzyme Linked Immunosorbent Assay (ELISA) was used to compare the protein accumulation levels in the

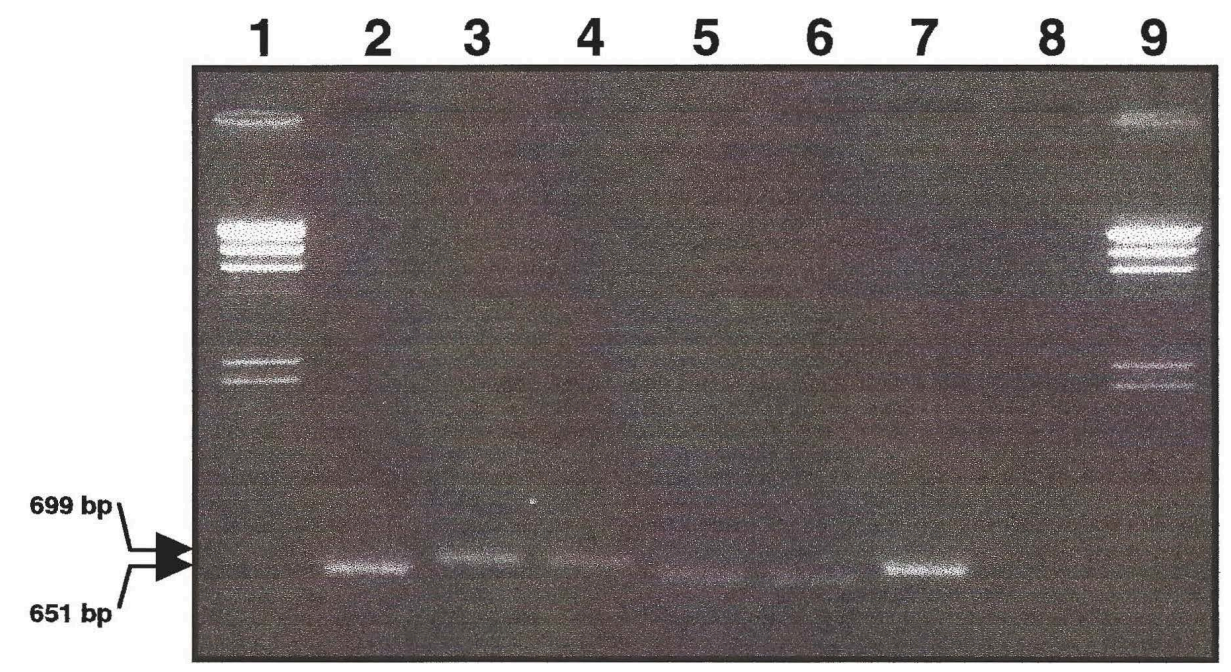

Figure 2. Amplification by PCR of the phaseolin coding regions in the T-DNA of transferred genes in the isolated tobacco DNA. The primers used should amplify a segment of the C-terminal half of the genes and allowed to distinguish pTRA 451, 454 and 455 (the amplified fragment is 651 bp in length) from pTRA 452, 453 and 456 (699 bp in length) with either loop-insertions or Helix-Turn-Helix insertion, as shown on Figure 1. Lanes 1 and 9, DNA molecular weight markers; lanes 2, 3, 4, 5, 6, 7, DNA samples were prepared from leaves of transgenic tobacco plants transformed by Agrobacterium tumefaciens containing binary vectors pTRA 451, 452, 453, 454, 455, and 456, respectively; and lane 8 , DNA sample from non-transformed control tobacco plants. 
Table 1. For each methionine-enhancement constructs listed are the number of methionines per phaseolin polypeptide (types of methionine-enhancement mutations), the number of independently transformed plants, the number of PCR-positive plants, and the number of ELISA phaseolin protein signal-positive plants.

\begin{tabular}{|c|c|c|c|c|}
\hline Constructs & $\begin{array}{l}\text { Number of methionines } \\
\text { (type of mutations) }\end{array}$ & $\begin{array}{l}\text { Independently } \\
\text { transformed plants }\end{array}$ & $\begin{array}{l}\text { PCR-positive } \\
\text { plants }\end{array}$ & $\begin{array}{l}\text { ELISA-phaseolin protein } \\
\text { positive plants }\end{array}$ \\
\hline pTRA 451 & 3 (positive control wild-type) & 22 & 20 & 13 \\
\hline pTRA 452 & 18 (two loop-insertions) & 18 & 16 & 0 \\
\hline pTRA 453 & $\begin{array}{c}8 \text { (negative control, Hoffman } \\
\text { helix-insertion) }\end{array}$ & 9 & 8 & 0 \\
\hline pTRA 454 & 13 (C-barrel substitution) & 12 & 10 & 0 \\
\hline pTRA 455 & $\begin{array}{l}23 \text { ( } \mathrm{N}-\& \mathrm{C} \text {-barrel } \\
\text { substitutions) }\end{array}$ & 19 & 10 & 0 \\
\hline pTRA 456 & $\begin{array}{l}33 \text { (two loop-insertions and N- } \\
\text { \& C-barrel substitutions) }\end{array}$ & 35 & 25 & 0 \\
\hline
\end{tabular}

four-week old seed extracts from 89 PCR-positive transgenic tobacco plants (Table 1). Thirteen seed extracts of pTRA 451 plants containing the wild-type phaseolin coding sequences showed the positive ELISA signals for phaseolin at the protein accumulation level expected [14]. The previous analysis indicated the level of protein accumulation measured by ELISA were at approximately $10 \mu \mathrm{g}$ of phaseolin per mg of protein in transgenic tobacco seeds when the wild-type phaseolin gene was expressed under the control of the 5'-promoter and 3'downstream elements [13]. ELISA-positive signal was not detectable in any seed extracts of pTRA 452, 453, 454, and 455 except for one seed extracts of pTRA 456 (clone IX 33A). Moreover, the positive responses were only obtained clearly with the original extracts and the one-tenth dilutions, when a rough estimate of the final concentration of phaseolin indicates that the protein should be detected in the one thousandth dilutions for the high expressing clones. However, the positive ELISA signal in the clone IX 33A found not reproducible when the other seed extracts were tested several times later on.

It is possible that the methionine enhancement mutations lender the mutated proteins less soluble by the extraction protocol we had used, or less detectable by antibody generated by the wild-type phaseolin protein prepared from the common bean seeds.

\section{Discussion}

The preliminary results based on ELISA analyses indicated that the methionine-enhanced phaseolins did not accumulate as stable as the wild-type phaseolin in the mature seeds of transgenic tobacco plants. The results are not in agreement with our expectations since we took very conservative approaches in designing the methionine-enhancement mutations [3]. We have also shown that biophysical analysis of $E$. coli-expressed monomeric non-glycosylated proteins had a similar structural stability of wild-type and mutant phaseolins [4]. This suggested that the nascent polypeptide folding and thermodynamic stability of monomeric proteins are similar between the wild-type and mutant proteins.

There are a number of potential sites where the methionine-enhanced phaseolin mutants might have been degraded during the course of post-translational modification from the initial entry to ER through Golgi complex and small transport vesicles to the final packaging into the vacuolar protein bodies. Phaseolin is synthesized on polysome of the rough endoplasmic reticulum (ER) in developing cotyledon of common beans [26] [27]. The nascent polypeptide enters the lumen of the ER where the signal peptide is cleaved co-translationally. The polypeptide is glycosylated by a high-mannose glycan $\mathrm{Glc}_{3} \mathrm{Man}_{9}(\mathrm{GlcNac})_{2}$, folded into the proper tertiary structure, and assembled into a trimer [28]. A Binding protein (BiP)-like chaperone associates the phaseolin monomer and mediates the proper folding and trimer assembly [29] [30]. The rate of trimer assembly is controlled by the number of N-linked oligosaccharide chains as well as by trimming of its terminal glucose residues of $\mathrm{Glc}_{3} \mathrm{Man}_{9}{ }^{-}$ $(\mathrm{GlcNac})_{2}$ [31]. Phaseolin trimers in small transport vesicles are transported from the ER to the Golgi complex either by default bulk-flow or active secretion via sorting receptors [32]. The conversion of the high-mannose glycan to complex glycan was used as evidence that the protein was transported through the medial/trans-cisternae of the Golgi complex [32]. Glycosylated phaseolin trimer is targeted to the vacuole and packaged into the protein body where the fragmentation of phaseolin has been observed [33]. The carboxyl terminal four amino 
acid residues AFVY act as the vacuole sorting signal and is removed from the protein upon the delivery to vacuole.

The ER protein quality control mechanism ensures to maintain a smooth flow of secretary proteins by preventing a traffic jam, if any [34]. The mechanism enforces the proper rate of folding speed of polypeptide chains, the rate of N-liked glycosylation, and the thermodynamic stability of trimer assembly. One of the initial events of ER protein quality control appears to involve the flagging of polypeptides by the mannose-residues at oxygen atom of serine or threonine residue of polypeptides when the ER protein quality control find the rate of protein folding too slow [35]. BiP, the ER chaperone protein and a member of the Heat Shock Protein 70 family, is associated with Sec61 translocon complex and interact co-translationally with nascent polypeptides. BiP was found to bind to the hydrophobic regions of monomeric phaseolin polypeptide to avoid the interaction of hydrophobic regions, thus preventing the aggregate formation of nascent polypeptides [36] [37].

ER proteins are then under the scrutiny of the protein folding apparatus of calnexin (CNX) and calreticulin (CRT) in which the protein glycan of the core oligosaccharide act as recognition signals for the entry to and exit from the apparatus [34]. Phaseolin polypeptide contains two glycosylation site recognition motifs (Asn-XSer/Thr) at position $\mathrm{Asn}^{228}$ and $\mathrm{Asn}^{317}$ located at the surface-exposed regions of the carboxyl $\beta$-barrel [15] [16]. The branched 14 sugar complex $\mathrm{Glc}_{3} \mathrm{Man}_{9}(\mathrm{GlcNAc})_{2}$ of lipid-linked oligosaccharides are transferred by oligosaccharyl transferase to the attachment site. Glucosidase I cleaves the outer most Glucose14, and glucosidae II removes the next two outer most Glucoses 13 and 12 sequentially. Protein disulfide isomerase joins the two-SH groups, if present, to the formation of disulfide bond-S-S-. The properly folded and glycosylated ER proteins are exported to Golgi complex while other ER proteins deemed unfit (unfolded and/or misfolded proteins) are degrade through ER-associated degradation (ERAD) [38].

The previous reports suggest glycosylation might play a role in structural stability of phaseolin [39]-[42]. Phaseolin is not uniformly glycosylated producing at least two glycoforms. One glycoform contains high-mannose glycans at both positions, $\mathrm{Man}_{7}(\mathrm{GlcNA})_{2}$ at $\mathrm{Asn}^{228}$ and $\mathrm{Man}_{9}(\mathrm{GlcNAc})_{2}$ at $\mathrm{Asn}^{317}$. A second glycoform contains a complex glycan Xyl-Man ${ }_{3}(\text { GlcNAc })_{2}$ at $\mathrm{Asn}^{228}$ and no glycosilation at $\mathrm{Asn}^{317}$ [39] [40]. The extent of glycosylation varies also among bean cultivars. The glycosylation-site knock-out experiment in transgenic tobacco has demonstrated that glycans are not required for proper transport to protein bodies [41]. When the double knock-out mutants of the glycosylation-sites were expressed in the insect Sf9 cells after Baculovirus infection, degradation products ( 34 and $37 \mathrm{kDa}$ ) of the mature proteins were detectable probably due to the endoproteolitic cleavages [42].

The effects of protein engineering or modifications of phaseolin protein have been studied in details using immunocytochemistry, light or/and electron microscopic analyses. "Hoffman insert" used in this study as a negative control consists of 15 amino acid residues including six methionines designed to form $\alpha$-helix structure (himet phaeolin). The Hoffman insert was introduced to the N-terminal Helix-Turn-Helix (HTH) motif ( $\alpha$-helix-2) of phaseolin protein. The modified phaseolin gene was transcribed into mRNA which was translated into polypeptide that was processed through post-translation modifications. The accumulation of modified phaseolin was reduced by 50 -fold in the mature transgenic tobacco seeds [14].

The addition of the ER-retention signals H/KDEL to the carboxyl-terminal of wild-type or himet phaseolin resulted in the increased abundance of protein due to the protein's interaction with an ER receptor and recycling of the protein between the Golgi apparatus and the ER [43] [44]. The addition of HDEL increased the abundance of immunocytochemical signals for himet phaseolin detectable in the ER, Golgi stack and transport vesicles to the vacuolar protein bodies, converting the HDEL protein more transport-competent. The himet phaseolin with HDEL accumulated in the vacuolar protein bodies at early stage of seed development and degraded by vacuolar proteases at mid to late maturation stages of seed development [43]. The addition of KDEL to the wild-type phaseolin markedly increased the stability of phaseolin and allowed a small portion of the protein slowly delivered to the vacuole via an alternative mechanism independent of trans-Golgi complex [44].

The two HTH motifs of phaseolin play an essential structural role in the hydrophobic interaction between the adjacent monomeric proteins and hold together the thermodynamically stable formation of the trimer assembly [15] [16]. The amino terminal HTH extends amino acid residues 156 to 181, and the carboxyl terminal HTH extends amino acid residues 340 to 371. The amino terminal HTH interacts with the carboxyl terminal HTH of interacting monomer to assemble a stable trimer complex. The substitution of the amino terminal HTH with the unstructured nine amino acids linker transformed the wild-type protein into the trimer-assembly-defective one which was susceptible to degradation by the ER quality control mechanism [45]. The carboxyl terminal 59 ami- 
no acid residues 336 to 397 include the carboxyl terminal HTH motif and the carboxyl end AFVY vacuolar sorting signal. The deletion of these 59 amino acid residues resulted in the monomeric trimer-assembly-defective protein. The carboxyl terminal HTH contains three BiP-binding motifs and is determined as binding domains for BiP chaperon. The deletion products were transportable out of ER to the vacuolar protein bodies [45]. More interestingly, the deletion of carboxyl terminal 26 amino acid residues also rendered the protein trimerassembly-defective. This deletion does not include the carboxyl terminal HTH motif, starting adjacent to the carboxyl terminal HTH and include the HTH-downstream sequence involving the interchain interactions with the second $\beta$-sheet domain. These interactions might involve in the proper positioning of the HTH in configuration needed for interchain contacts [45]. Thus, the thermodynamically stable formation of trimer assembly appears to require not only the presence of amino- and carboxyl-terminal HTH motifs but also the adjacent sequences assisting the proper positioning of these HTH motifs in the stable formation of trimer assembly.

It should be noted that the methionine-substitutions are targeted to the region of amino acid residues 82 to 122 in the N-barrel (40 amino acids) and the region of residues 264 to 313 in the C-barrel (50 amino acids) [3]. Molecular simulation of the substitution mutations on the three-dimensional structure of phaseolin revealed that the mutation sites were located almost exclusively within the core of the $\beta$-barrel structures, and not at the interface region between the barrels. It would be interesting to know that the methionine-enhanced phaseolins could assemble a stable trimer when expressed in the insect Sf9 cells after baculovirus infection [42], and if so to compare the biophysical parameters of trimer stability between the wild-type and methionine-enhanced phaseolins.

\section{Conclusion}

The methionine-enhanced phaseolins did not accumulate stably in transgenic tobacco seeds. It is probable or likely that the methionine enhancement mutations might have reduced the efficiency of the assembly processes of monomeric proteins into the trimeric mature form by somehow distorting the proper positioning of HTH from the tertiary structure of the wild-type trimer assembly.

\section{Acknowledgements}

This work was supported in part by grants from USDA-NRI Competitive Grant program 95-37301-1829, and from Louisiana Education Quality Support Fund (1994-97)-RD-B8 to NM. The authors also appreciated receiving the financial assistances from the Louisiana State University, College of Agriculture, and LSU Agricultural Center, Department of Plant Pathology and Crop Physiology.

\section{References}

[1] Loesch Jr, P.J., Foley, D.C. and Cox, D.F. (1976) Comparative Resistance of opaque-2 and Normal Inbred Lines of Maize to Ear-Rotting Pathogens. Crop Science, 16, 841-842.

[2] Delaney, D.E. and Bliss, F.A. (1991) Selection for Increased Percentage Phaseolin in Common Bean. 1. Comparison of Selection for Seed Protein Alleles and S1 Family Recurrent Selection. Theoretical Applied Genetics, 81, 301-305. http://dx.doi.org/10.1007/BF00228667

[3] Dyer, J.M., Nelson, J.W. and Murai, N. (1993) Strategies for Selecting Mutation Sites for Methionine Enhancement in the Bean Seed Storage Protein Phaseolin. Journal Protein Chemistry, 12, 545-560. http://dx.doi.org/10.1007/BF01025119

[4] Dyer, J.M., Nelson, J.W. and Murai, N. (1995) Extensive Modifications for Methionine Enhancement in the $\beta$-Barrels Do Not Alter the Structural Stability of the Bean Storage Protein Phaseolin. Journal Protein Chemistry, 14, 665-677. http://dx.doi.org/10.1007/BF01886905

[5] Sun, S.M., Mutschler, M.A., Bliss, F.A. and Hall, T.C. (1978) Protein Synthesis and Accumulation in Bean Cotyledons during Growth. Plant Physiology, 61, 918-923. http://dx.doi.org/10.1104/pp.61.6.918

[6] Bellini, R. and Chrispeels, M.J. (1978) Characterization and Subcellular Localization of Vicilin and Phytohemagglutinin, the Two Major Reserve Proteins of Phaseolus vulgaris L. Planta, 142, 291-298. http://dx.doi.org/10.1007/BF00385080

[7] Talbot, D.R., Adang, M.J., Slightom, J.L. and Hall, T.C. (1984) Size and Organization of a Multigene Family Encoding phaseolin, the Major Seed Storage Protein of Phaseolus vulgaris. Molecular General Genetics, 198, 42-49. http://dx.doi.org/10.1007/BF00328698

[8] Anthony, J.L., VonderHaar, R.A. and Hall, T.C. (1990) Nucleotide Sequence of an $\alpha$-Phaseolin Gene from Phaseolus 
vulgaris. Nucleic Acid Research, 18, 11. http://dx.doi.org/10.1093/nar/18.11.3396

[9] Sun, S.M., Mcleester, R.C., Bliss, F.A. and Hall, T.C. (1974) Reversible and Irreversible Dissociation of Globulins from Phaseolus vulgaris Seed. Journal of Biological Chemistry, 249, 2118-2121.

[10] Sun, S.M., Slightom, J.L. and Hall, T.C. (1981) Intervening Sequences in a Plant Gene-Comparison of the Partial Sequence of cDNA and Genomic DNA of French Bean Phaseolin. Nature, 289, 37-41. http://dx.doi.org/10.1038/289037a0

[11] Slightom, J.L., Sun, S.M. and Hall, T.C. (1983) Complete Nucleotide Sequence of a French Bean Storage Protein Gene: Phaseolin. Proceedings of the National Academy of Sciences of the United States of America, 80, 1897-1901. http://dx.doi.org/10.1073/pnas.80.7.1897

[12] Bustos, M.M., Begum, D., Kalkan, F.A., Battrawand, M.J. and Hall, T.C. (1991) Positive and Negative cis-Acting DNA Domains Are Required for Spatial and Temporal Regulation of Gene Expression by a Seed Storage Protein Promoter. European Molecular Biology Organization Journal, 10, 1469-1479.

[13] Burow, M.D., Sen, P., Chlan, C.A. and Murai, N. (1992) Developmental Control of the $\beta$-Phaseolin Gene Requires Positive, Negative, and Temporal Seed-Specific Transcriptional Regulatory Elements and a Negative Element for Stem and Root Expression. Plant Journal, 2, 537-548. http://dx.doi.org/10.1111/j.1365-313X.1992.00537.x

[14] Hoffman, L.M., Donaldson, D.D. and Herman, E.M. (1988) A Modified Storage Protein Is Synthesized, Processed, and Degraded in the Seeds of Transgenic Plants. Plant Molecular Biology, 11, 717-729. http://dx.doi.org/10.1007/BF00019513

[15] Lawrence, M.C., Izard, T., Beuchat, M., Blagroveand, R.J. and Colman, P.M. (1994) Structure of Phaseolin at $2 \cdot 2 \AA$ Resolution: Implications for a Common Vicilin/Legumin Structure and the Genetic Engineering of Seed Storage Proteins. Journal of Molecular Biology, 238, 748-776. http://dx.doi.org/10.1006/jmbi.1994.1333

[16] Lawrence, M.C., Suzuki, E., Varghese, J.N., Davis, P.C., Van Donkelaar, A., Tulloch, P.A. and Colman, P.M. (1990) The Three-Dimensional Structure of the Seed Storage Protein Phaseolin at $3 \AA$ Resolution. European Molecular Biology Organization Journal, 9, 9-15.

[17] Dyer, J.M., Nelsonand, J.W. and Murai, N. (1992) Biophysical Analysis of Phaseolin Denaturation Induced by Urea, Guanidinium Chloride, $p \mathrm{H}$, and Temperature. Journal of Protein Chemistry, 11, 281-288. http://dx.doi.org/10.1007/BF01024867

[18] Sengupta-Gopalan, C., Reichert, N.A., Barker, R.F., Halland, T.C. and Kemp, J.D. (1985) Developmentally Regulated Expression of the Bean $\beta$-Phaseolin Gene in Tobacco Seed. Proceedings of the National Academy of Sciences of the United States of America, 82, 3320-3324. http://dx.doi.org/10.1073/pnas.82.10.3320

[19] Greenwood, J.S. and Chrispeels, M.J. (1985) Correct Targeting of the Bean Storage Protein Phaseolin in the Seeds of Transformed Tobacco. Plant Physiology, 79, 65-71.

[20] Barker, S.J., Harada, J.J. and Goldberg, R.B. (1988) Cellular Localization of Soybean Storage Protein mRNA in Transformed Tobacco Seeds. Proceedings of the National Academy of Sciences of the United States of America, 85, 458-462. http://dx.doi.org/10.1073/pnas.85.2.458

[21] Marcellino, L.H., Neshich, G., Grossi de Sá, M.F., Krebbers, E. and Gander, E.S. (1996) Modified 2S Albumins with Improved Tryptophan Content Are Correctly Expressed in Transgenic Tobacco Plants. Federation of European Biochemical Societies Letter, 385, 154-158. http://dx.doi.org/10.1016/0014-5793(96)00375-4

[22] Burow, M.D., Chlan, C.A., Sen, P., Lisca, A. and Murai, N. (1990) High-Frequency Generation of Transgenic Tobacco Plants after Modified Leaf Disk Cocultivation with Agrobacterium tumefaciens. Plant Molecular Biology Reporter, 8, 124-139. http://dx.doi.org/10.1007/BF02669766

[23] Sen, P., Chlan, C.A., Burow, M.D., Lee, W.S. and Murai, N. (1993) Apical and Lateral Shoot Apex-Specific Expression Is Conferred by Promoter of the Seed Storage Protein $\beta$-Phaseolin Gene. Transgenic Research, 2, 21-28. http://dx.doi.org/10.1007/BF01977677

[24] Sambrook, D., Fritsh, E.F. and Maniatis, T. (1989) Molecular Cloning: A Laboratory Manual. 2nd Edition, Cold Spring Harbor Laboratory Press, Cold Spring Harbor Laboratory.

[25] Wang, H., Meiqing, Q.L. and Cutler, A.J. (1993) A Simple Method of Preparing Plant Samples for PCR. Nucleic Acids Research, 21, 4153-4154. http://dx.doi.org/10.1093/nar/21.17.4153

[26] Bollini, R. and Chrispeels, M.J. (1979) The Rough Endoplasmic Reticulum Is the Site of Reserve Protein Synthesis in Developing Phaseolus vulgaris Cotyledons. Planta, 146, 487-501. http://dx.doi.org/10.1007/BF00380865

[27] Bollini, R., van der Wilden, W. and Chrispeels, M.J. (1982) A Precursor of the Reserve-Protein, Phaseolin, Is Transiently Associated with the Endoplasmic Reticulum of Developing Phaseolus vulgaris Cotyledons. Physiologia Plantarum, 55, 82-92. http://dx.doi.org/10.1111/j.1399-3054.1982.tb02268.x

[28] Bollini, R., Vitale, A. and Chrispeels, M.J. (1983) In Vivo and in Vitro Processing of Seed Reserve Protein in the Endoplasmic Reticulum: Evidence for Two Glycosylation Steps. Journal of Cell Biology, 96, 999-1007. 
http://dx.doi.org/10.1083/jcb.96.4.999

[29] D’Amico, L., Valsasina, B., Daminati, M.G., Fabbrini, M.S., Nitti, G., Bollini, R., Ceriotti, A. and Vitale, A. (1992) Bean Homologs of the Mammalian Glucose-Regulated Proteins: Induction by Tunicamycin and Interaction with Newly Synthesized Seed Storage Proteins in the Endoplasmic Reticulum. Plant Journal, 2, 443-455.

[30] Ceriotti, A., Pedrazzini, E., Bielli, E., Giovinazzo, A., Bollini, R. and Vitale, A. (1995) Assembly and Intracellular Transport of Phaseolin, the Major Storage Protein of Phaseolus vulgaris L. Journal of Plant Physiology, 145, 648-653. http://dx.doi.org/10.1016/S0176-1617(11)81277-0

[31] Lupattelli, F., Pedrazzini, E., Bollini, R., Vitale, A. and Ceriotti, A. (1997) The Rate of Phaseolin Assembly Is Controlled by the Glucosylation State of Its N-Linked Oligosaccharide Chains. Plant Cell, 9, 597-609. http://dx.doi.org/10.1105/tpc.9.4.597

[32] Chrispeels, M.J. (1991) Sorting of Proteins in the Secretory System. Annual Review of Plant Physiology and Plant Molecular Biology, 42, 21-53. http://dx.doi.org/10.1146/annurev.pp.42.060191.000321

[33] Frigerio, L., de Virgillio, M., Prada, A., Faoro, F. and Vitale, A. (1998) Sorting of Phaseolin to the Vacuole Is Saturable and Requires a Short C-Terminal Peptide. Plant Cell, 10, 1031-1042. http://dx.doi.org/10.1105/tpc.10.6.1031

[34] Liu, J.-X. and Howell, S.H. (2010) Endoplasmic Reticulum Protein Quality and Its Relationship to Environmental Stress Responses in Plants. Plant Cell, 22, 2930-2942. http://dx.doi.org/10.1105/tpc.110.078154

[35] Xu, C., Wang, S., Thibault, G. and Ng, D.T.W. (2013) Futile Protein Folding Cycles in the ER Are Terminated by the Unfolded Protein O-Mannosylation Pathway. Science, 340, 978-981. http://dx.doi.org/10.1126/science.1234055

[36] Pedrazzini, E., Giovinazzo, G., Bollini, R., Ceriotti, A. and Vitale, A. (1994) Binding of BiP to an Assembly-Defective Protein in Plant Cells. Plant Journal, 5, 103-110. http://dx.doi.org/10.1046/j.1365-313X.1994.5010103.X

[37] Vitale, A., Bielli, A. and Ceriotti, A. (1995) The Binding Protein Associates with Monomeric Phaseolin. Plant Physiology, 107, 1411-1418.

[38] Smith, M.H., Ploegh, H.L. and Weissman, J.S. (2011) Road to Ruin: Targeting Proteins for Degradation in the Endoplasmic Reticulum. Science, 334, 1086-1090. http://dx.doi.org/10.1126/science.1209235

[39] Sturm, A., Van Kuk, J.A., Vliegenthart, J.F.G. and Chrispeels, M.J. (1987) Structure, Position, and Biosynthesis of the High Mannose and the Complex Oligosaccharide Side-Chains of the Bean Storage Protein Phaseolin. Journal of Biological Chemistry, 262, 13392-13403.

[40] Sturm, A., Johnson, K.D., Szumilo, T., Elbein, A.D. and Chrispeels, M.J. (1987) Subcellular Localization of Glycosidases and Glycosyltransferases Involved in the Processing of N-Linked Oligosaccharides. Plant Physiology, 85, 741746. http://dx.doi.org/10.1104/pp.85.3.741

[41] Bustos, M.M., Kalkan, F.A., Vanden Bosch, K.A. and Hall, T.C. (1991) Differential Accumulation of Four Phaseolin Glycoforms in Transgenic Tobacco. Plant Molecular Biology, 16, 381-395. http://dx.doi.org/10.1007/BF00023990

[42] Harada, T., Miyairi, K. and Murai, N. (2010) Trimeric Glycoproteins of Bean Seed Storage Protein Phaseolin Were Purified from Baculovirus-Infected Insect Sf9 Cells for Use of Structural Study. Plant Science, 179, 123-132.

[43] Pueyo, J.J., Chrispeels, M.J. and Herman, E.M. (1995) Degradation of Transport-Competent Destabilized Phaseolin with a Signal for Retention in the Endoplasmic Reticulum Occurs in the Vacuole. Planta, 196, 586-596. http://dx.doi.org/10.1007/BF00203660

[44] Figerio, L., Pastres, A., Prada, A. and Vitale, A. (2001) Influence of KDEL on the Fate of Trimeric or Assembly-Defective Phaseolin: Selective Use of an Alternative Route to Vacuoles. Plant Cell, 13, 1109-1126. http://dx.doi.org/10.1105/tpc.13.5.1109

[45] Foresti, O., Frigerio, L., Holkeri, H., de Virgilio, M., Vavassori, S. and Vitale, A. (2003) A Phaseolin Domain Involved Directly in Trimer Assembly Is a Determinant for Binding of the Chaperone BiP. Plant Cell, 15, 2464-2475. http://dx.doi.org/10.1105/tpc.013052

\section{Abbreviations}

BiP, binding protein;

ER, endoplasmic reticulum;

ELISA, enzyme-linked immunosorbent assay;

HTH, helix-turn-helix;

PAGE, polyacrylamide gel electrophoresis;

PB, protein bodies. 